\title{
Article \\ Static and Dynamic Analysis of a 6300 KN Cold Orbital Forging Machine
}

\author{
Zhiqiang Gu ${ }^{1,2,3, *}$, Mingzhang Chen ${ }^{1,2,3}$, Chaoyang Wang ${ }^{1,2,3}$ and Wuhao Zhuang ${ }^{1,2,3}$ \\ 1 School of Automotive Engineering, Wuhan University of Technology, Wuhan 430070, China; \\ chenmingzhang@whut.edu.cn (M.C.); whut_wangchaoyang@163.com (C.W.); \\ zhuangwuhao204@126.com (W.Z.) \\ 2 Hubei Key Laboratory of Advanced Technology for Automobile Components, \\ Wuhan University of Technology, Wuhan 430070, China \\ 3 Hubei Collaborative Innovation Center for Automotive Components Technology, \\ Wuhan University of Technology, Wuhan 430070, China \\ * Correspondence: zhiqianggu0609@whut.edu.cn
}

check for updates

Citation: Gu, Z.; Chen, M.; Wang, C.; Zhuang, W. Static and Dynamic Analysis of a 6300 KN Cold Orbital Forging Machine. Processes 2021, 9, 7. https://dx.doi.org/10.3390/pr9010007

Received: 16 November 2020 Accepted: 8 December 2020 Published: 22 December 2020

Publisher's Note: MDPI stays neutral with regard to jurisdictional claims in published maps and institutional affiliations.

Copyright: () 2020 by the authors. Licensee MDPI, Basel, Switzerland. This article is an open access article distributed under the terms and conditions of the Creative Commons Attribution (CC BY) license (https: / / creativecommons.org/ licenses/by/4.0/).

\begin{abstract}
In cold orbital forging (COF) processes, large stress, displacement and vertical vibration of the COF machine are bad for the quality of the part and the fatigue life of the COF machine. It is necessary to investigate the static and dynamic performance of the COF machine and provide methods for reducing the stress, displacement and vertical vibration of the COF machine. In this paper, finite element analysis, theoretical analysis, numerical simulation and experimental analysis were applied to study the static and dynamic performance of a $6300 \mathrm{KN}$ COF machine. The static and dynamic analyses were verified effectively by carrying out strain and vertical vibration test experiments. In the static analysis, the large stress and displacement positions of the COF machine were mainly distributed near the working table and the junction between the working table and the column. Large stress and displacement will be bad for the quality of the part and the fatigue life of the COF machine. Structural optimizations of the COF machine include ribbed plates on the working table and beam. This structural optimization method of the COF machine obviously reduced the stress and displacement of the COF machine. When the angular velocities of the eccentric rings were $8 \pi \mathrm{rad} / \mathrm{s}$, the vertical vibration of the swing shaft is a low-frequency vibration. The existence of absorber obviously reduced the vertical vibration of the COF machine.
\end{abstract}

Keywords: cold orbital forging; finite element analysis; theoretical analysis; numerical simulation; experimental analysis; static analysis; machine vibration; dynamic model

\section{Introduction}

Cold orbital forging (COF) is an advanced and complicated metal forming technology [1]. Compared with conventional forging technology, COF can reduce forming force, improve the flowing capability of metal and improve the loading state of the die. Hence, COF is widely used to manufacture mechanical parts such as disks, rings, flanges and gears. However, in the COF process, large stress, large displacement and vertical vibration of the COF machine are bad for the quality of the part and the fatigue life of the COF machine. In order to improve the quality of the part and the fatigue life of the COF machine, investigations into the static performance and dynamic performance of the COF machine and methods of reducing stress displacement and vertical vibration are necessary.

In recent years, some research on static and dynamic analysis of mechanical components and structures has been carried out. In the static analysis aspect, Jiao et al. [2] studied static stiffness and modal analysis of a large machine with the software Hyperworks. Fu et al. [3] researched the static performance of a drilling machine. Markowski et al. [4] investigated the static performance of a clinching joint machine by finite element analysis. Syam et al. [5] studied the static properties of a machine frame and carried out 
experimental verification. Irfan et al. [6] reviewed finite element model development and the recent research trends of finite element formulations developed for analyzing sandwich plates. Gohari et al. [7] applied finite element analysis to investigate crack initiation and unstable crack growth of the part resulting from gas pressure and the accompanying gas temperature in the gas forming process. Sherbakov [8] applied finite element analysis and theoretical analysis to study the three-dimensional stress-strain state of a pipe with corrosion damage under complex loading. Sherbakov et al. [9] constructed and analyzed equations for determining the three-dimensional stress-strain state for a multi-component system of solids. Shcherbakov [10,11] established the mechanical and mathematical model of a stress-strain state system subjected to action of contact and non-contact loads and studied the change in the coefficient of rolling resistance as a function of the level of contact and non-contact bending loads.

In the dynamic analysis aspect, Sosnovskiy et al. [12] substantiated and formulated the main principles of the physical discipline mechanothermodynamics that united Newtonian mechanics and thermodynamics. Li et al. [13] carried out dynamic modal analysis of machine tool structures. Liu et al. [14] and Bar et al. [15] established a vertical dynamic model of cold rolling machines with non-linear external excitation. Lu et al. $[16,17]$ established a vertical dynamic model and a horizontal dynamic model, and the accuracy of the dynamic model was verified by comparing the results of the simulation and experiments. Kim et al. [18,19] investigated several influencing factors of vibration on a rolling machine and the results showed that a small rolling force, a small rotation speed of work roll and small chatter frequency contributed to reducing the vibration of the rolling machine.

Based on research into static and dynamic analyses of mechanical components and structures, ref. [20-25] investigated some effective structure optimization methods for improving the performance of machines. However, investigations into the COF machine are mainly investigations of the deformation mechanism, forging force and kinematic mechanism of COF [26-33], and few investigations into the static performance and dynamic performance of the COF machine have been carried out.

The objective of this paper was to investigate the static performance and dynamic performance of a $6300 \mathrm{KN} \mathrm{COF}$ machine by finite element analysis, theoretical analysis, numerical simulation and experimental analysis. By analyzing the static and dynamic performance of the COF machine, we find that the large stress positions of the COF machine are mainly distributed near the working table and the junction between the working table and the inside of the column. Large displacement positions are mainly distributed near the upper and lower working tables. The maximum equivalent stress of the COF machine is less than the allowable stress of the material of the COF machine. In the COF process, material yield will not take place in the COF machine. The minimum modal frequency of the COF machine is higher than the excitation frequency of the COF machine. Resonance will not take place on the COF machine and the COF process is stable. When the angular velocities of the inner and outer eccentric rings are $8 \pi \mathrm{rad} / \mathrm{s}$, the peak values of the frequency-domain curve of vertical vibration arose at $4 \mathrm{~Hz}$ and $61 \mathrm{~Hz}$ and the vertical vibration of the swing shaft is a low-frequency vibration. In order to verify the accuracy of the static and dynamic analysis of the COF machine, strain and vertical vibration test experiments on a $6300 \mathrm{KN}$ COF machine were carried out. According to the large stress positions and the large displacement positions of the COF machine, a structural optimization method for the COF machine is put forward to reduce stress and displacement. Based on the vertical dynamic model, the absorber is set to reduce vertical vibration. The structural optimization method and the existence of the absorber obviously reduced stress, displacement and vertical vibration in the COF machine.

\section{Static Analysis of COF Machine}

The large load and high-speed stamping frequency produced in operation of the COF machine will introduce deformation of the COF machine, influence quality of the part, and 
reduce the life of the COF machine. It is crucial to analyze the static performance of the COF machine under nominal pressure.

\subsection{Static Stress and Displacement Analysis of the COF Machine}

The structure of a $6300 \mathrm{KN}$ COF machine can be seen in Figure 1. The COF machine is made of carbon structural steel (Q235). The elasticity modulus, Poisson ratio and the density of material are $210,000 \mathrm{MPa}, 0.31$ and $0.00000000785 \mathrm{t} / \mathrm{mm}^{3}$, respectively. The finite element mesh of the COF machine is shown in Figure 2. The mesh element type is a quadratic tetrahedral element C3D10. The total number of nodes and elements is 369,524 and 219,114 , respectively.

In the COF process, the upper and lower dies contact the part directly. COF force is transferred to lower working table through the lower die. COF force is transferred to the upper working table through the upper die and the swing shaft bearing. In static performance analysis, boundary constraints and loads are shown in Figure 3. Displacement of the undersurface of the COF machine is constrained as zero displacement. The load on the COF machine is nominal pressure $(6300 \mathrm{KN})$ on the COF machine, and the load is applied on upper and lower working tables.

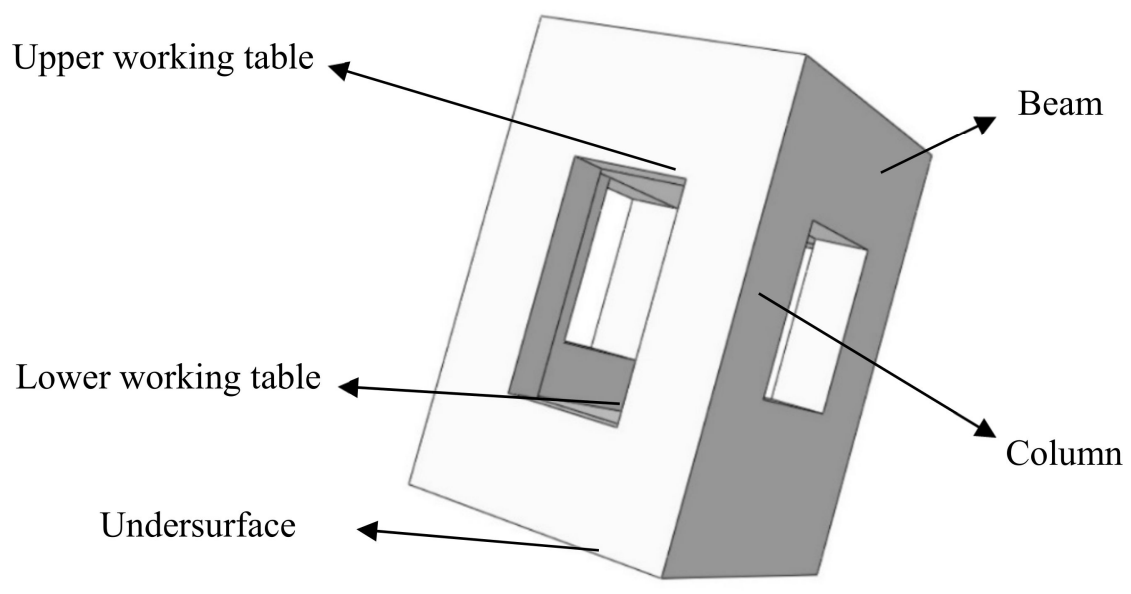

(a)

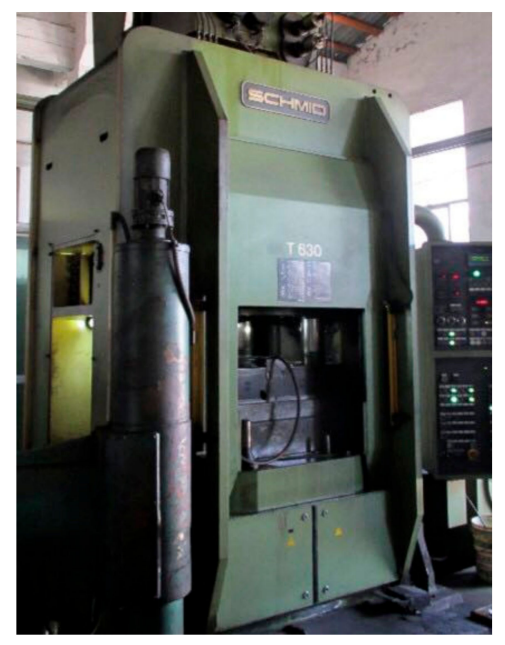

(b)

Figure 1. Structure (a) and equipment (b) of the $6300 \mathrm{KN}$ cold orbital forging (COF) machine. 


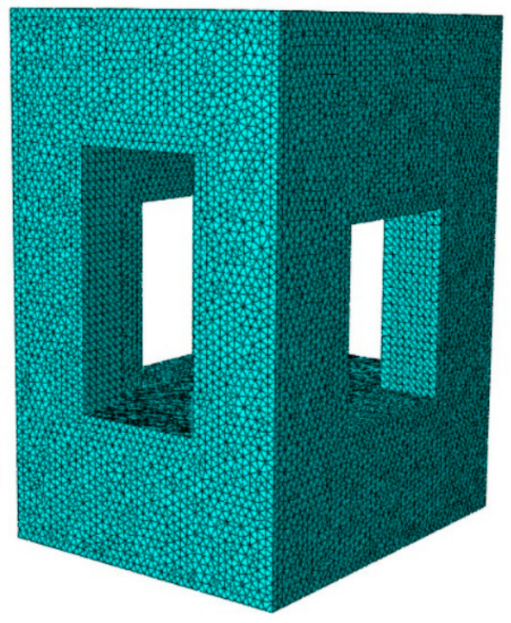

Figure 2. Finite element mesh of the COF machine.

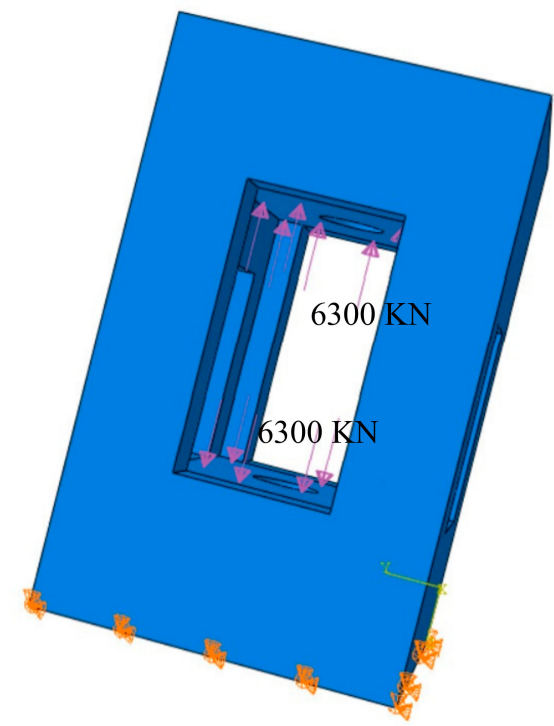

Figure 3. Boundary conditions of the COF machine.

In order to analyze the distribution of stress and displacement inside the COF machine, half of the COF machine was applied to analyze the distribution of the stress and the displacement. The equivalent stress distribution of the COF machine is shown in Figure 4.
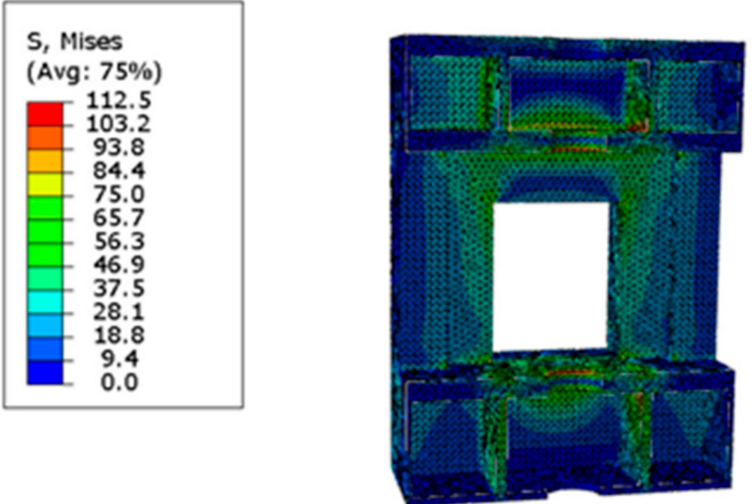

Figure 4. Equivalent stress distribution of the COF machine. 
As shown in Figure 4, the maximum equivalent stress value of the COF machine is 112.5 MPa. When plastic material suffers from static load, the value range of the safety coefficient of plastic material is 1.2-2.5. The material of the COF machine is the plastic material (16Mn) and the yield stress of $16 \mathrm{Mn}$ is $345 \mathrm{MPa}$. The allowable stress of the material of the COF machine can be calculated by Equation (1).

$$
[\sigma]=\frac{\sigma_{S}}{n}=\frac{345}{2.5}=138(\mathrm{MPa})
$$

where $[\sigma]$ is allowable stress of material of the COF machine $(\mathrm{MPa}), \sigma_{S}$ is the yield stress of the material of the COF machine (MPa) and $n$ is the safety coefficient of the material of the COF machine. The maximum equivalent stress value of the COF machine is less than the allowable stress of material of the COF machine.

Figure 5 shows the positions (non-black positions) where the equivalent stress is more than $40 \mathrm{MPa}, 50 \mathrm{MPa}$ and $60 \mathrm{MPa}$. In the black positions, the equivalent stress is minor and stiffness problems are less likely to exist. Large stress positions (Positions 1-6 in Figure 6) are mainly distributed near the working table and the junction between the working table and the inside of the column.
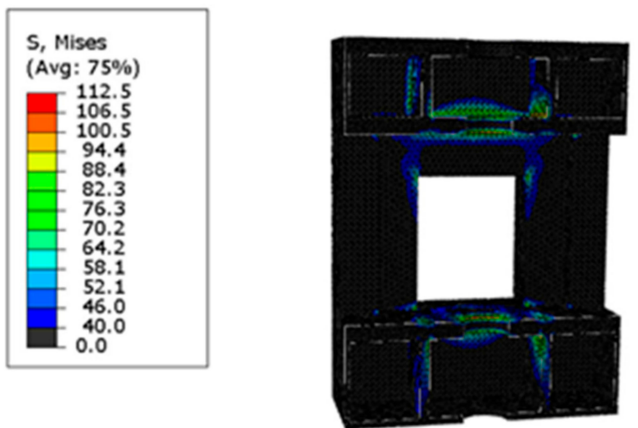

(a)
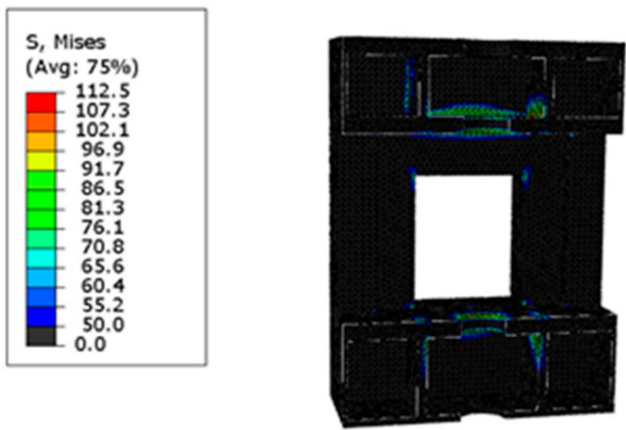

(b)
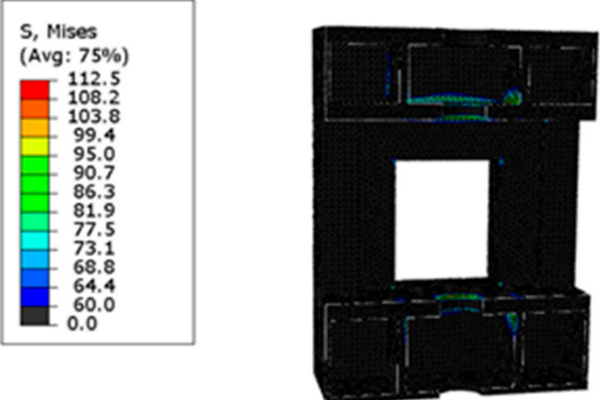

(c)

Figure 5. Positions where the equivalent stress is more than $40 \mathrm{MPa}(\mathbf{a}), 50 \mathrm{MPa}$ (b) and $60 \mathrm{MPa}$ (c). 


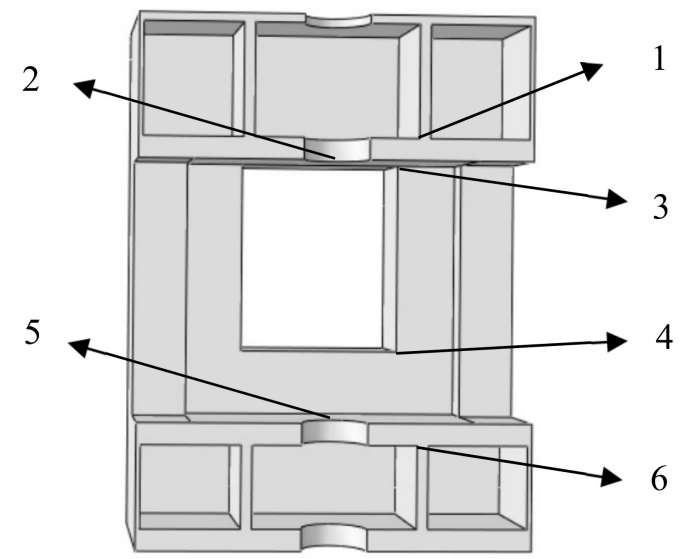

Figure 6. Large stress positions of the COF machine.

The equivalent stresses of Positions 1-6 are shown in Table 1 . The equivalent stress of Position 5 is maximum in the COF machine, and the equivalent stress of Position 5 is less than the allowable stress of the material of the COF machine. Therefore, in the COF process, material yield will not take place in the COF machine. However, the equivalent stresses of Positions 1-6 are large and will reduce the quality of the part and the fatigue life of the COF machine.

The displacement of the COF machine is shown in Figure 7. Z-scale displacement of the COF machine is more obvious than the $x$-scale displacement and the $y$-scale displacement. The large displacement positions (Positions 7-10 in Figure 8) are mainly distributed near the upper and lower working tables, and the displacement of Position $8(0.7267 \mathrm{~mm})$ is the maximum in the COF machine. Large displacements of Positions 7-10 will be bad for the quality of the part and the fatigue life of the COF machine.
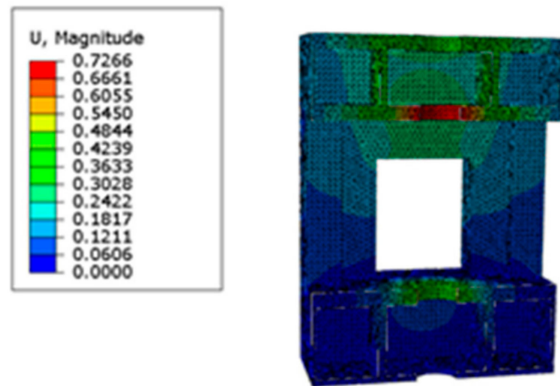

(a)

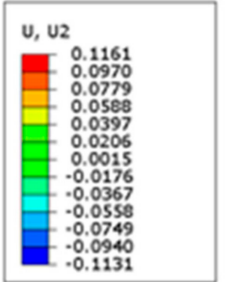

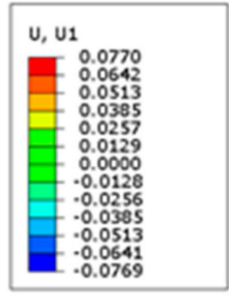

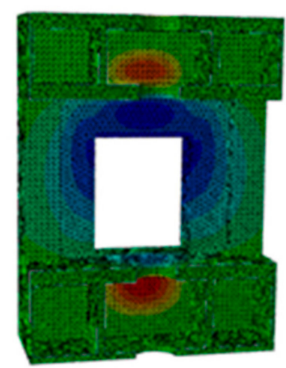

(c)

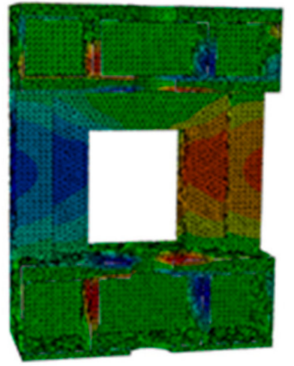

(b)
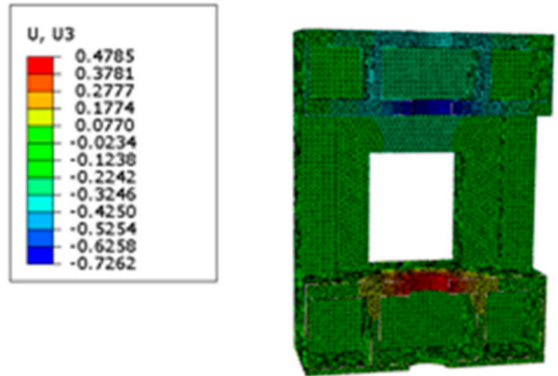

(d)

Figure 7. Main displacement (a), x-scale displacement (b), y-scale displacement (c) and z-scale displacement (d) of the COF machine. 


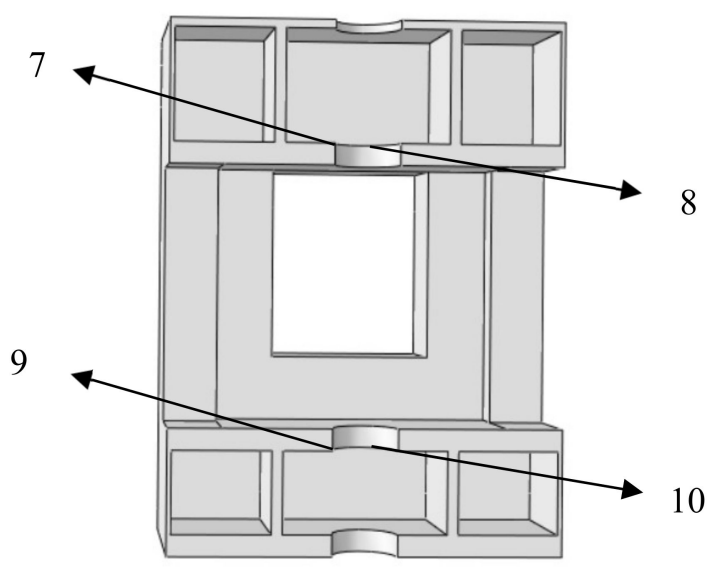

Figure 8. Large displacement positions of the COF machine.

Table 1. Equivalent stresses of Positions 1-6.

\begin{tabular}{lcccccc}
\hline Position Number & $\mathbf{1}$ & $\mathbf{2}$ & $\mathbf{3}$ & $\mathbf{4}$ & $\mathbf{5}$ & $\mathbf{6}$ \\
\hline Equivalent stress & $108.067 \mathrm{MPa}$ & $98.219 \mathrm{MPa}$ & $93.036 \mathrm{MPa}$ & $104.176 \mathrm{MPa}$ & $112.521 \mathrm{MPa}$ & $105.080 \mathrm{MPa}$ \\
\hline
\end{tabular}

\subsection{Static Modal Analysis of theCOF Machine}

In the static modal analysis, the boundary condition of the COF machine is shown in Figure 9. Displacement of the undersurface of the COF machine is constrained as zero displacement. No other boundary constraint or load exists on the COF machine.

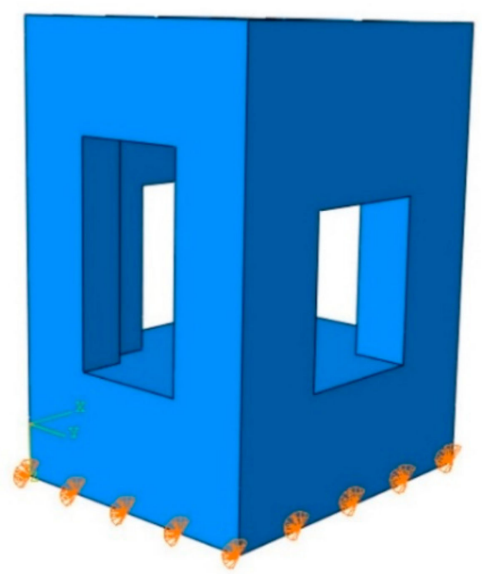

Figure 9. Boundary condition of the COF machine.

The first 10 orders of modal vibration of the COF machine are shown in Figure 10. In first-order and second-order modals vibrations, large $x$-scale displacement and large $y$-scale displacement exist on the COF machine. The upper and lower dies cannot be kept in alignment. The quality of the part will be affected and the dies will get worn. In third-order modal vibrations, the machine contorts around the $z$-axis. The forging stability of the part will be affected. In fourth-order modal vibrations, local vibration takes place on the top surface of the COF machine. In the fifth-order and sixth-order modal vibrations, $x$-scale displacement and y-scale displacement exist on the COF machine and the displacement is more obvious than the displacement in the first-order and second-order modal vibrations. The upper and lower dies cannot be kept in alignment. The quality of the part will be affected the and dies will get worn. In the seventh-order, eighth-order, ninth-order and 
tenth-order modal vibrations, local vibration occurs on the column of the COF machine. The local vibration is drastic and noise will easily happen.
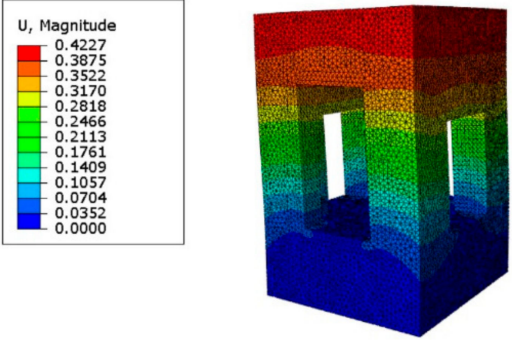

(a) First-order modal vibration
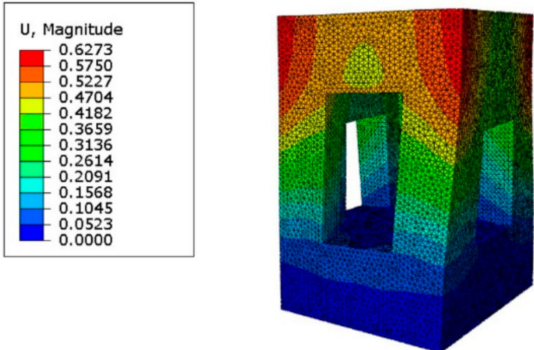

(c) Third-order modal vibration
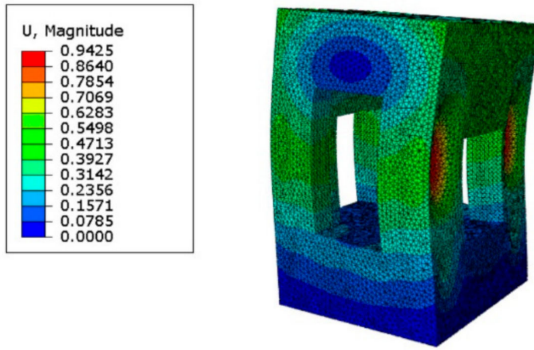

(e) Fifth-order modal vibration
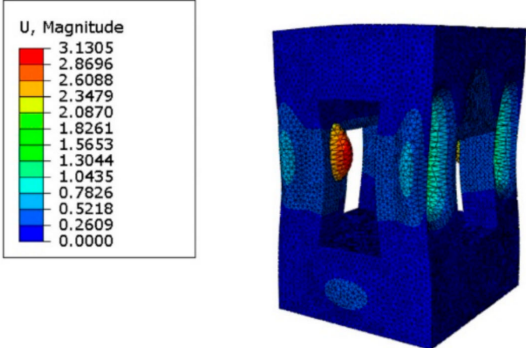

(g) Seventh-order modal vibration
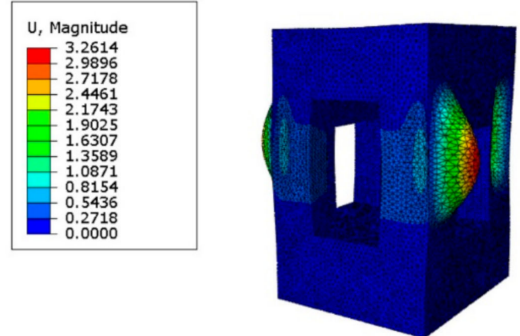

(i) Ninth-order modal vibration
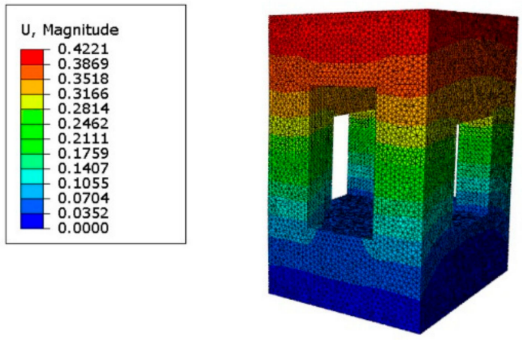

(b) Second-order modal vibration.
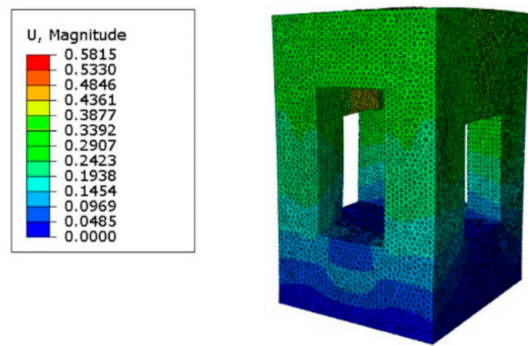

(d) Fourth-order modal vibration
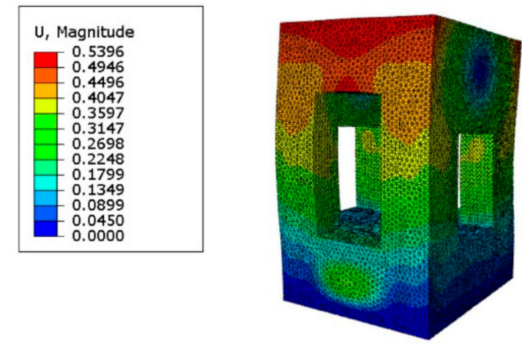

(f) Sixth-order modal vibration
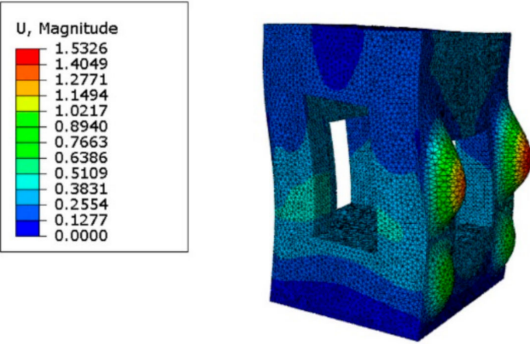

(h) Eighth-order modal vibration
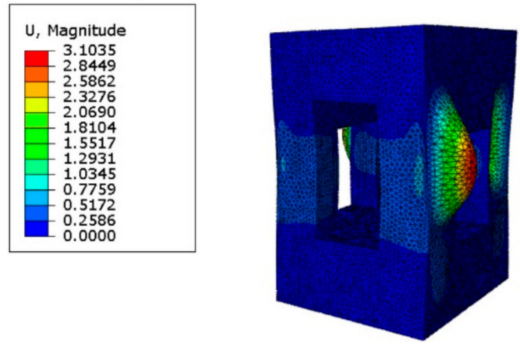

(j) Tenth-order modal vibration

Figure 10. First 10 orders of modal vibrations of the COF machine.

The first 10 orders of modal frequency of the COF machine are $71.702 \mathrm{~Hz}, 99.525 \mathrm{~Hz}$, $126.92 \mathrm{~Hz}, 324.30 \mathrm{~Hz}, 339.94 \mathrm{~Hz}, 406.92 \mathrm{~Hz}, 418.56 \mathrm{~Hz}, 422.38 \mathrm{~Hz}, 425.48 \mathrm{~Hz}$ and $427.77 \mathrm{~Hz}$. In the COF process, the revolving speed of the swing shaft is $4 \mathrm{r} / \mathrm{s}$, and the excitation 
frequency is $4 \mathrm{~Hz}$. The minimum modal frequency $(71.702 \mathrm{~Hz})$ of the COF machine is higher than the excitation frequency. Resonance will not take place on the COF machine and the COF process is stable.

\section{Dynamic Analysis of the COF Machine}

The structures of the critical components of the $6300 \mathrm{KN} \mathrm{COF}$ machine can be seen in Figure 11. During the COF process, the swing shaft of the COF machine contacts the forging part. The movement of the swing shaft directly influences the forging of the part.

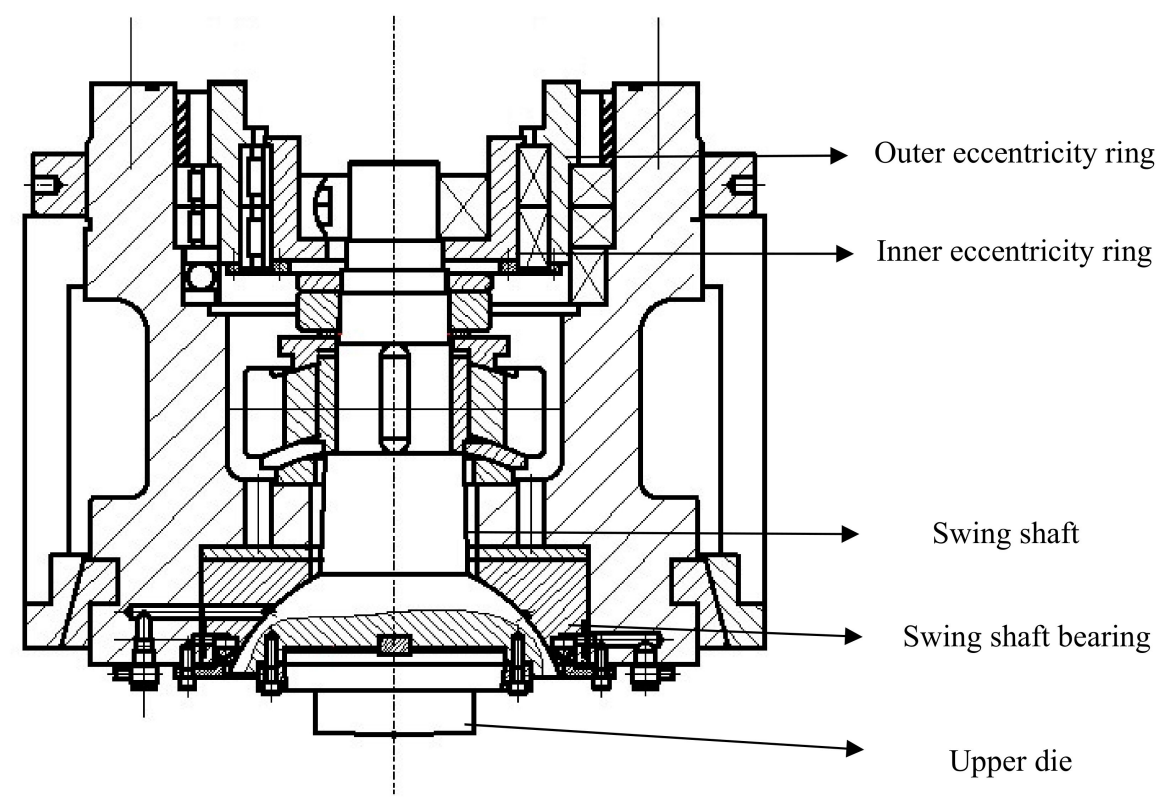

Figure 11. Structures of the critical components of the $6300 \mathrm{KN} \mathrm{COF}$ machine.

Figure 12 provides the structure of the swing shaft. The swing shaft consists of two cylinders and a cone; the cone represents the upper die; $r_{04}$ and $r_{05}$ are the radius $(\mathrm{m})$ of the upper cylinder and the middle cylinder, respectively; $d_{1}, d_{2}$ and $d_{3}$ are the height $(\mathrm{m})$ of the upper cylinder, the middle cylinder and the cone, respectively. The total height of the swing shaft (L) can be expressed by Equation (2).

$$
L=d_{1}+d_{2}+d_{3}
$$
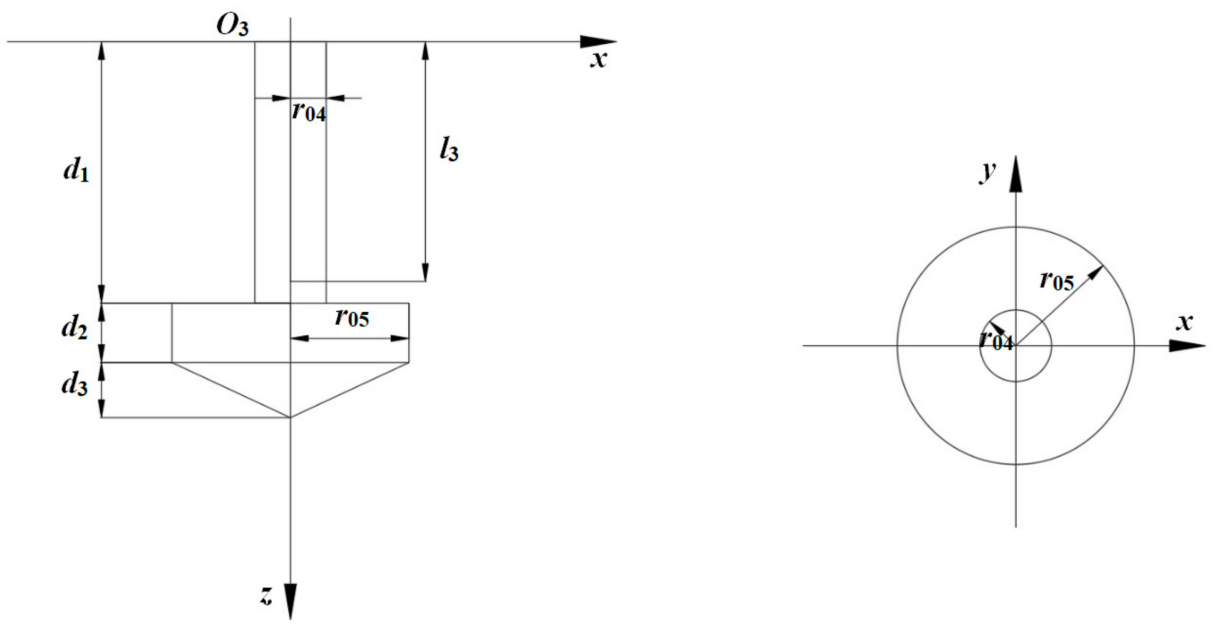

Figure 12. Structure of the swing shaft. 
The barycenter of the swing shaft (point $B_{3}$ ) is on the rotation axis of the swing shaft. The mass of the swing shaft $\left(m_{3}\right)$ can be calculated by Equation (3).

$$
m_{3}=\pi \rho_{0}\left(r_{04}^{2} d_{1}+r_{05}^{2} d_{2}+r_{05}^{2} d_{3} / 3\right)
$$

A vertical dynamic model of the swing shaft is shown in Figure 13. The vertical dynamic model is simplified as a spring-damping-mass model, and the concentrated mass is equivalent to the swing shaft. Here, $k_{1}$ is the equivalent stiffness between the swing shaft and the swing shaft bearing $(\mathrm{N} / \mathrm{m}), c_{1}$ is the equivalent damping between the swing shaft and the swing shaft bearing $(\mathrm{N} \cdot \mathrm{S} / \mathrm{m})$ and $z_{3}$ is the vertical displacement of the swing shaft $(\mathrm{m})$, of which the vertically upward direction is the positive direction of vertical displacement. The thickness of the cylindrical part after COF $(h, \mathrm{~m})$ can be calculated by $h=h_{0}+z_{3}$ and $h_{0}$ represents the thickness of the cylindrical part after COF, ignoring the effect of vibration $(\mathrm{m})$; $v$ is the vertical movement velocity of the forging part provided by the hydraulic system $(\mathrm{m} / \mathrm{s}), P$ is the COF force $(\mathrm{N})$ and $T$ is the vertical external excitation of the swing shaft $(T=F \sin \omega t, \mathrm{~N})$.

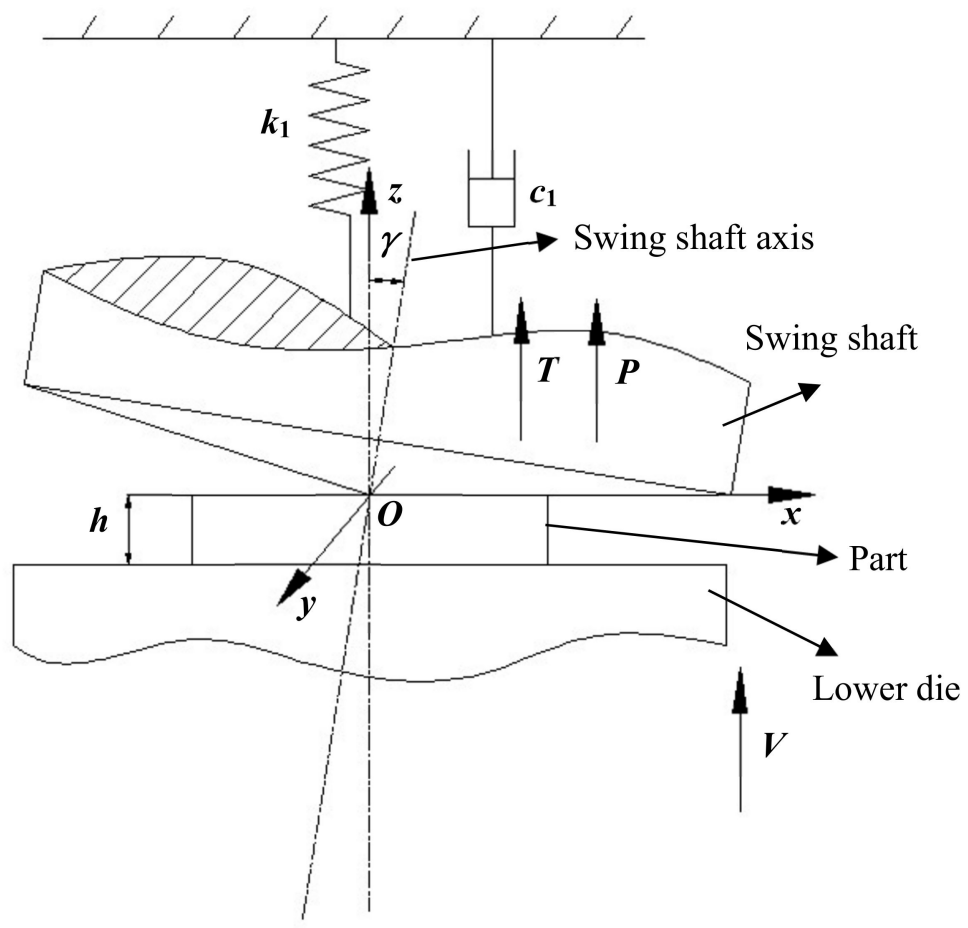

Figure 13. Vertical dynamic model of the swing shaft.

The COF force $(P)$ can be calculated by the following equation:

$$
P=10 n_{H} S n_{\sigma} \sigma_{s}
$$

where $n_{H}$ is the limit coefficient of the die, $S$ is the contact area between the swing shaft and the forging part $\left(\mathrm{mm}^{2}\right), n_{\sigma}$ is the stress state coefficient of the contact surface between the swing shaft and the forging part and $\sigma_{s}$ is the yield stress of the forging part. $S$ and $n_{\sigma}$ can be calculated by the following:

$$
\begin{gathered}
S=\frac{4}{3 \pi} \theta^{2}\left(1+\frac{1}{\theta}\right)^{\frac{3}{2}} \pi R_{0}^{2} \\
n_{\sigma}=1+\frac{0.414}{1-\theta}+\frac{m R_{0}}{1000 h}\left(0.72 \theta^{2}+0.591 \theta+0.0987\right)
\end{gathered}
$$


$R_{0}$ represents the radius of the forging part $(\mathrm{mm})$ and $m$ is the friction factor of plastic deformation. The relative movement of the lower die $(\theta)$ can be calculated by Equation (7).

$$
\theta=\frac{s}{2 R_{0} \tan \gamma}
$$

where $s$ is the lower die's movement of each turn ( $\mathrm{mm}$ ), and $\gamma$ is angle between the swing shaft axis and the $z$ axis.

In the process of elastoplastic deformation, $\mathrm{COF}$ force and displacement conform to the non-linear hysteresis due to the effect of periodic external excitation. The Taylor-series of $P$ near $z_{3}=0$ is expanded as follows:

$$
P\left(z_{3}\right)=P(0)+z_{3} \frac{\partial}{\partial z_{3}} P(0)+\frac{1}{2 !} z_{3}^{2} \frac{\partial^{2}}{\partial z_{3}^{2}} P(0)+\frac{1}{3 !} z_{3}^{3} \frac{\partial^{3}}{\partial z_{3}^{3}} P(0)+O\left(z_{3}^{4}\right)
$$

where $P(0)$ represents the steady-state COF force and $\Delta P\left(z_{3}\right)$ is the COF non-linear hysteretic force, which can be expressed by Equation (9).

$$
\Delta P\left(z_{3}\right)=b_{1} z_{3}+b_{2} z_{3}^{2}+b_{3} z_{3}^{3}
$$

$b_{1}, b_{2}$ and $b_{3}$ can be expressed by the equation below:

$$
\left\{\begin{array}{l}
b_{1}=\frac{\partial}{\partial z_{3}} P(0) \\
b_{2}=\frac{1}{2 !} \frac{\partial^{2}}{\partial z_{3}^{2}} P(0) \\
b_{3}=\frac{1}{3 !} \frac{\partial^{3}}{\partial z_{3}^{3}} P(0)
\end{array}\right.
$$

By combining Equations (8)-(10), $P$ can be expressed by the following equation:

$$
P\left(z_{3}\right)=P(0)+\Delta P\left(z_{3}\right)
$$

According to the generalized dissipation Lagrange principle, the vertical dynamic equation of the swing shaft can be expressed by Equation (12).

$$
m_{3} \ddot{z}_{3}+c_{1} \dot{z}_{3}+k_{1}\left(z_{3}+z_{0}\right)-P\left(z_{3}\right)=T
$$

where $z_{0}$ is the equilibrium point in the COF process. In the process of steady-state COF $\left((T=0), z_{3}=0, \dot{z}_{3}=0, \ddot{z}_{3}=0\right)$, the equilibrium equation below can be obtained:

$$
k_{1} z_{0}-P(0)=0
$$

By introducing Equations (9), (11) and (13) into Equation (12), the following equation can be obtained:

$$
m_{3} \ddot{z}_{3}+c_{1} \dot{z}_{3}+k_{1} z_{3}-b_{1} z_{3}-b_{2} z_{3}^{2}-b_{3} z_{3}^{3}=T
$$

Equation (14) can be converted into Equation (15):

$$
\ddot{z}_{3}+\omega_{0}^{2} z_{3}-\alpha z_{3}^{2}-\beta \dot{z}_{3}-\eta z_{3}^{3}=T_{0}
$$

where $\omega_{0}, \alpha, \beta, \eta$ and $T_{0}$ can be expressed by the following:

$$
\omega_{0}=\sqrt{\frac{k_{1}-b_{1}}{m_{3}}} \alpha=\frac{b_{2}}{m_{3}} \beta=-\frac{c_{1}}{m_{3}} \eta=\frac{b_{3}}{m_{3}} T_{0}=\frac{T}{m_{3}}=\frac{F \sin \omega t}{m_{3}}=F_{0} \sin \omega t
$$

The parameters of $6300 \mathrm{KN}$ COF machine are shown in Table 2, bringing COF machine parameters into the vertical dynamic model, so numerical simulation solutions can be 
obtained. Fast Fourier transform (FFT) is a kind of transformation method. FFT can transform a vertical acceleration time-domain curve into a vertical acceleration frequencydomain curve. After FFT of the vertical acceleration time-domain curve, the vertical acceleration frequency-domain curve of the swing shaft can be obtained, shown in Figure 14. As shown in Figure 14, the peak values of the frequency-domain curve of vertical vibration arise at $4 \mathrm{~Hz}$ and $61 \mathrm{~Hz}$, and the vertical vibration of the swing shaft is a low-frequency vibration.

Table 2. Parameters of the 6300 KN COF machine.

\begin{tabular}{cc}
\hline Parameter & Value \\
\hline Upper cylinder radius of the swing shaft $\left(r_{04}, \mathrm{~m}\right)$ & 0.105 \\
Middle cylinder radius of the swing shaft $\left(r_{05}\right)$ & 0.2625 \\
Upper cylinder height of the swing shaft $\left(d_{1}, \mathrm{~m}\right)$ & 0.805 \\
Middle cylinder height of the swing shaft $\left(d_{2}, \mathrm{~m}\right)$ & 0.245 \\
Cone height of the swing shaft $\left(d_{3}, \mathrm{~m}\right)$ & 0.0875 \\
Density of steel $\left(\rho_{0}, \mathrm{~kg} / \mathrm{m}^{3}\right)$ & 7900 \\
Equivalent stiffness $\left(k_{1}, \mathrm{~N} / \mathrm{m}\right)$ & $9.763 \times 10^{7}$ \\
Equivalent damping $\left(c_{1}, \mathrm{~N} \cdot \mathrm{S} / \mathrm{m}\right)$ & $1.073 \times 10^{4}$ \\
\hline
\end{tabular}

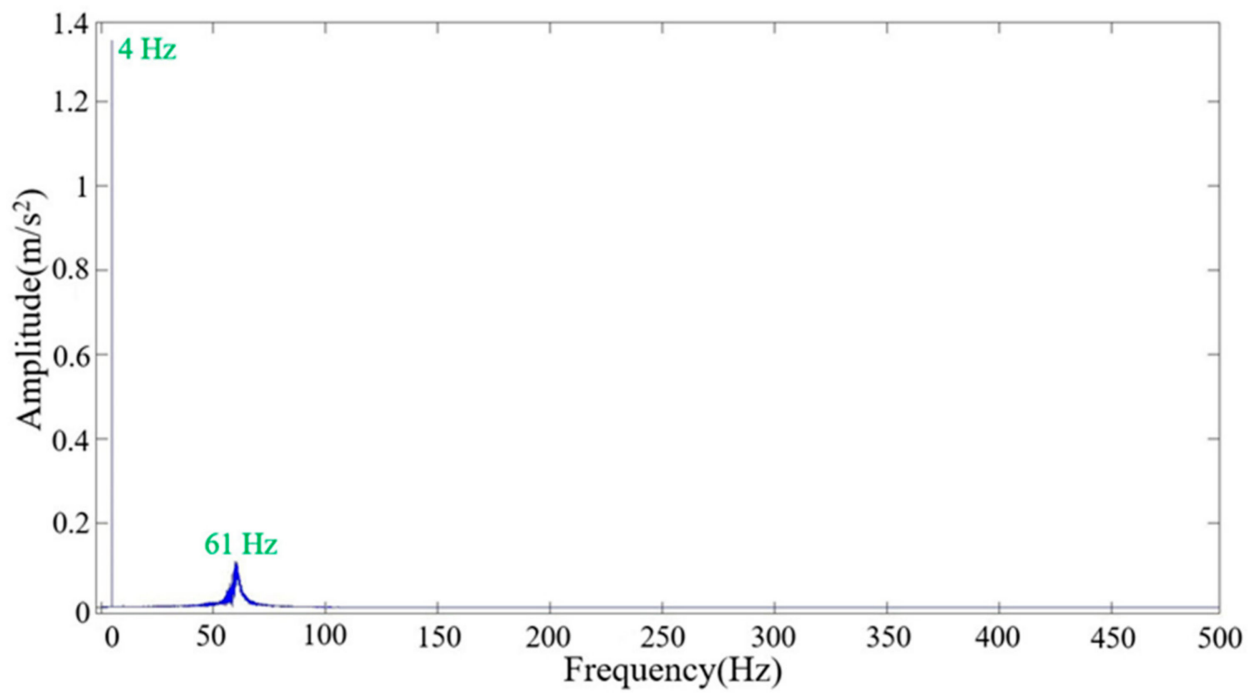

Figure 14. Vertical acceleration frequency-domain curve of the swing shaft.

\section{Experiment Verification}

\subsection{Experimental Verification of the Static Analysis}

In order to verify the effectiveness of the static analysis of the COF machine, a strain test experiment with the COF machine was carried out. The strain at Positions 11-14 (Figure 15) was tested to verify the effectiveness of the static analysis.

As shown in Figure 16, a strain test experiment was carried out on a 6300 KN COF machine to verify the effectiveness of the static analysis. In the strain test experiment, the value of the initial thickness of the part was $0.05 \mathrm{~m}$ and the value of the radius of the forging part was $0.038 \mathrm{~m}$. During the COF process, the strain of the COF machine was acquired by a strain gage and the strain signal was transmitted to the strain tester. The strain values of Positions 11-14 can be viewed and analyzed in the testing software. During the COF process, the strain values of Positions 11-14 were time-varying and the maximum strain value of each position was recorded. 


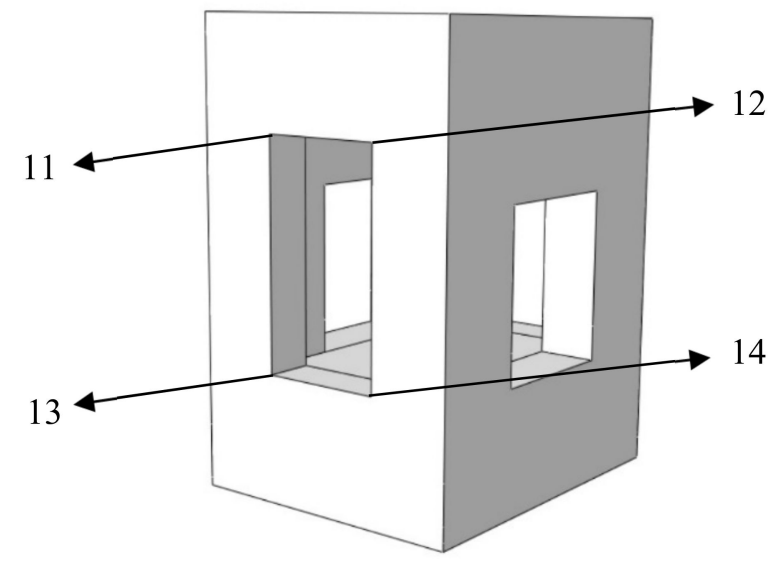

Figure 15. Positions of strain test.

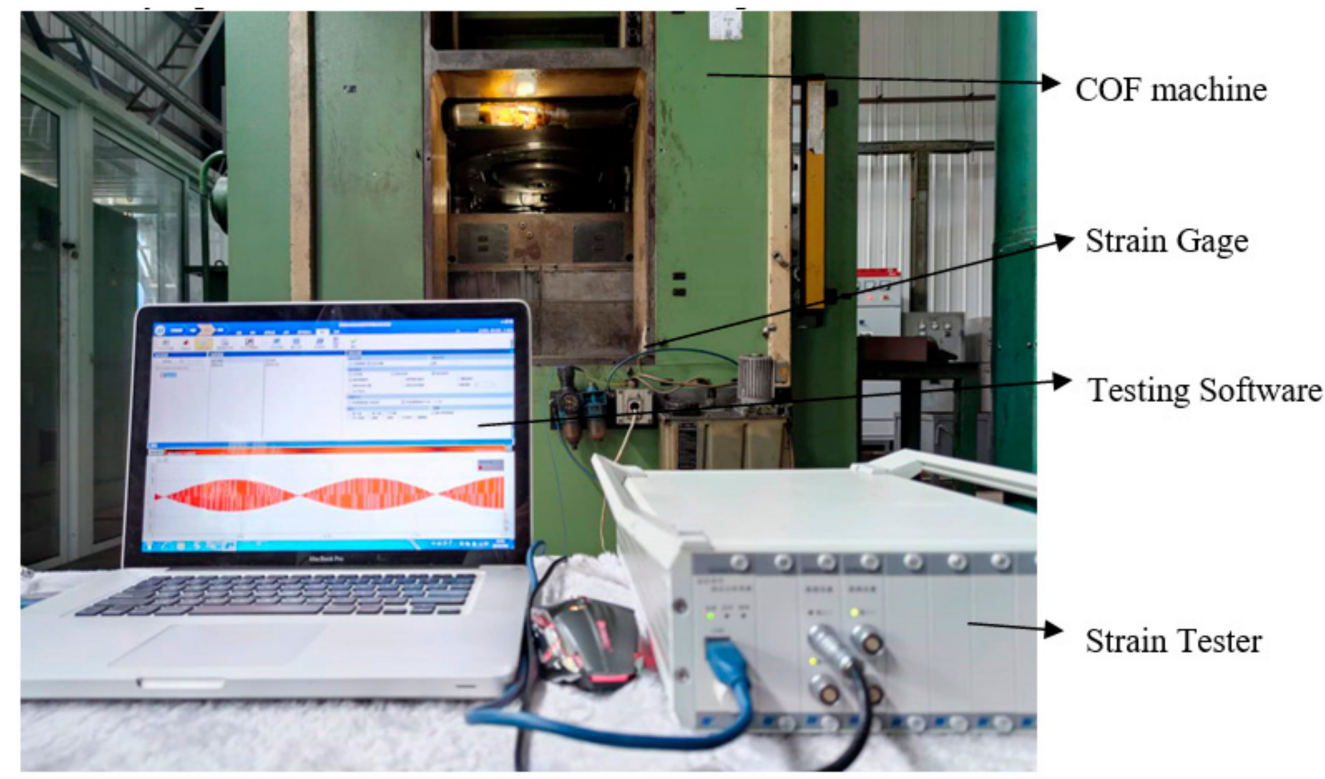

Figure 16. Strain test experiment.

The simulation strain values and the experimental strain values of Positions 11-14 are shown in Table 3. The error rates between simulation strain values and the experimental strain values were less than $10 \%$. The static analysis of the COF machine was verified effectively.

Table 3. Comparison between the simulation strain values and the experimental strain values of the COF machine.

\begin{tabular}{ccccc}
\hline Position Number & $\mathbf{1 1}$ & $\mathbf{1 2}$ & $\mathbf{1 3}$ & $\mathbf{1 4}$ \\
\hline Simulation value & 0.000147 & 0.000132 & 0.000034 & 0.000035 \\
Experimental value & 0.000153 & 0.000141 & 0.000031 & 0.000037 \\
Error rate & $4.08 \%$ & $6.81 \%$ & $-8.82 \%$ & $5.71 \%$ \\
\hline
\end{tabular}

\subsection{Experimental Verification of the Dynamic Analysis}

As shown in Figure 17, a verification experiment was carried out on a $6300 \mathrm{KN} \mathrm{COF}$ machine to verify the effectiveness of the dynamic model. The main equipment used for the verification experiment is shown in Table 4. In the experimental process, the angular velocities of the inner eccentric ring and the outer eccentric ring were $8 \pi \mathrm{ad} / \mathrm{s}$ and the hydraulic system drove the forging part to move upwards. In Figure 18, a unidirectional 
acceleration sensor is installed on the swing shaft. The unidirectional acceleration sensor applied in the experiment was a piezoelectric unidirectional acceleration sensor (ICP). The working principle of a piezoelectric unidirectional acceleration sensor is that the embedded piezoelectric wafer is extruded by the shell mass during movement, thus generating a voltage signal. Subsequently, the voltage signal will be converted into a charge signal to achieve acceleration signal acquisition and processing. During the COF process, the vertical acceleration signal of the swing shaft is acquired by an acceleration sensor, and the vertical acceleration signal was transmitted to an LMS signal acquisition instrument. $V$ The vertical acceleration signal of the swing shaft can be viewed and analyzed in LMS.Test.Lab software. Furthermore, in the verification experiment, it is necessary to avoid interference caused by the relative movement between the data line and the swing shaft. The data line should be a shielded line to avoid mutual interference between data lines. Meanwhile, the data line should be fixed to avoid shaking, and the data line fixed on the ground should avoid being compressed.

Table 4. Main equipment used for the verification experiment.

\begin{tabular}{ccc}
\hline Equipment & Type & Quantity \\
\hline Acceleration sensor & Piezoelectric unidirectional acceleration sensor & 1 \\
Data line & Shielded line & 10 \\
Signal acquisition instrument & LMS signal acquisition instrument & 1 \\
Computer & Computer installed with LMS.Test.Lab software & 1 \\
Auxiliary equipment & Desk, paper and pen & 1 \\
\hline
\end{tabular}

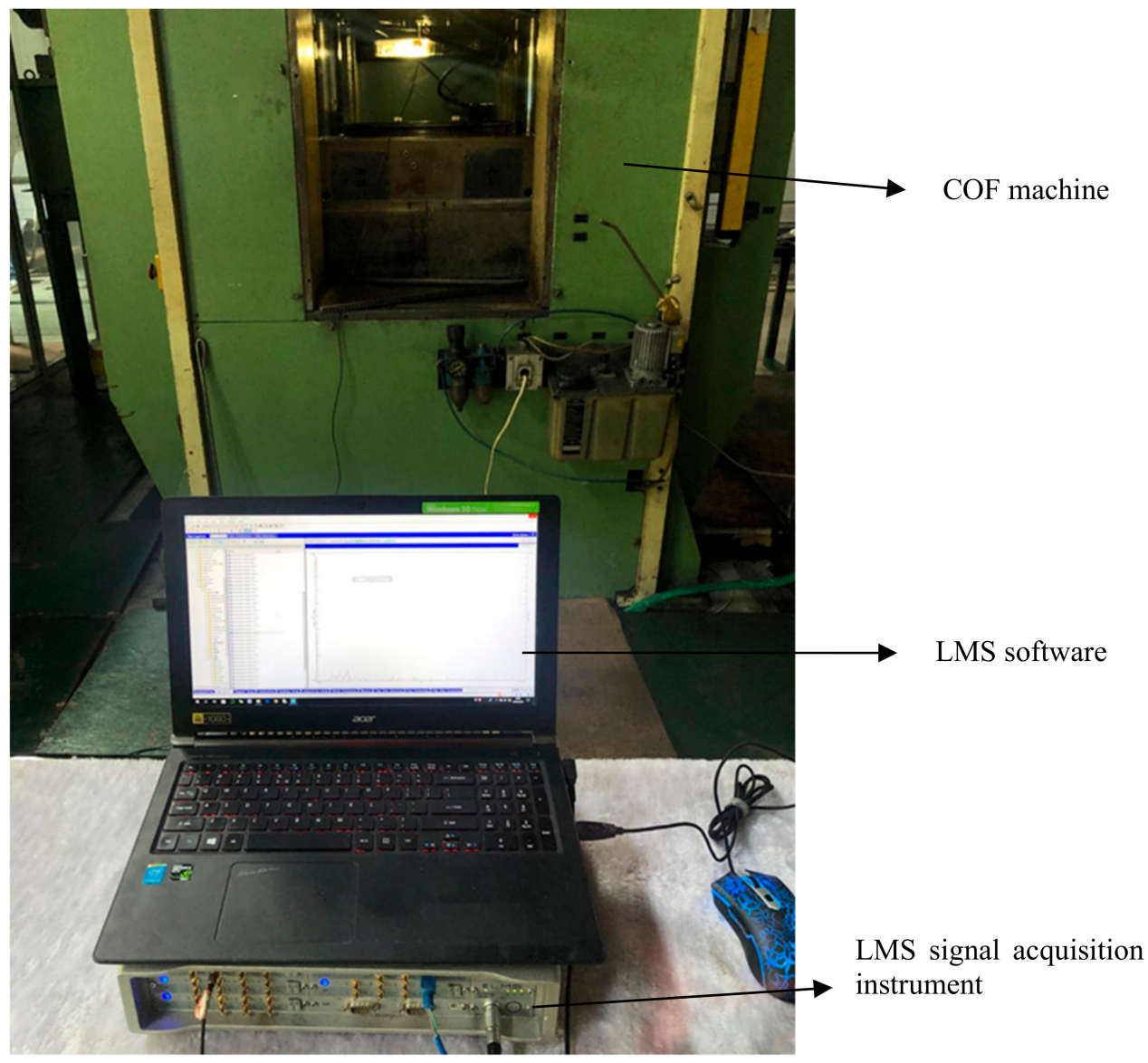

Figure 17. Verification experiment of the dynamic model. 


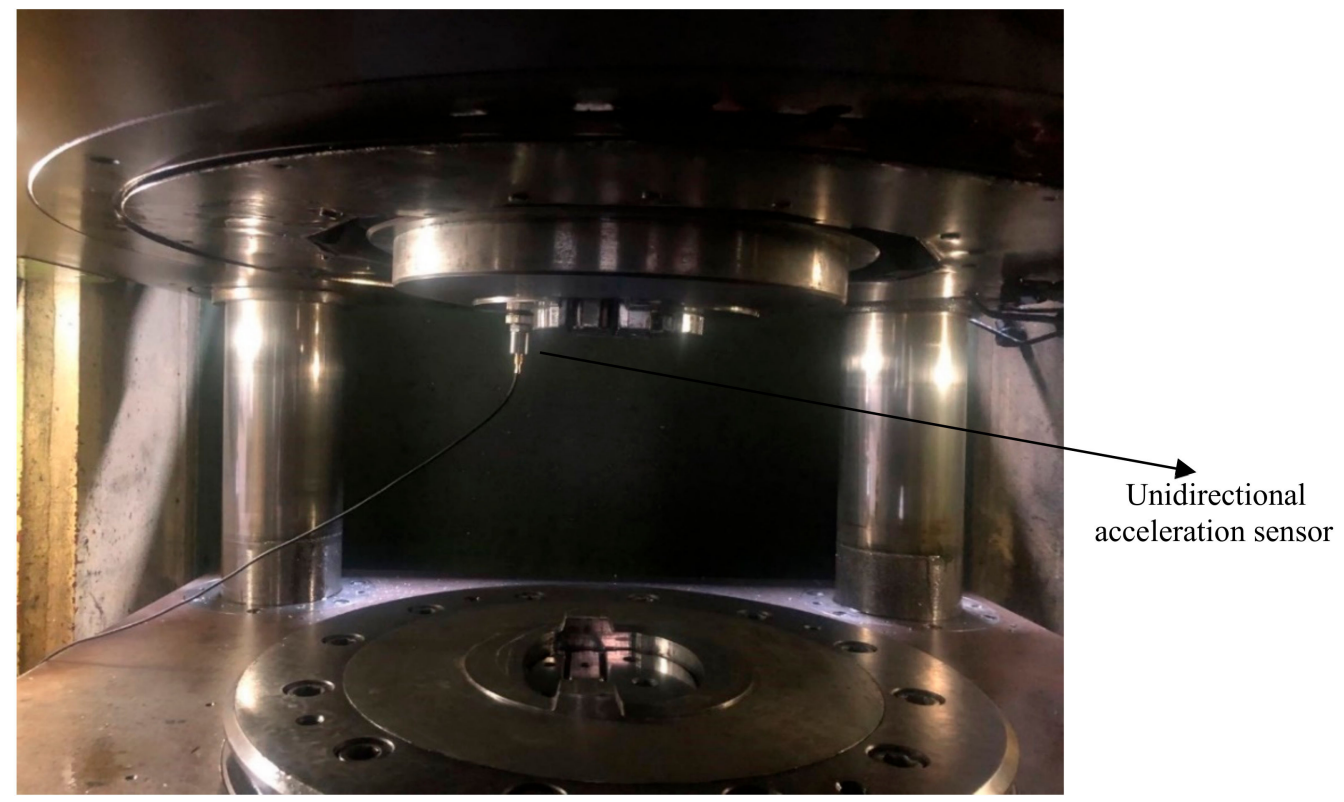

Figure 18. Installation site of the unidirectional acceleration sensor.

In LMS software, the vertical acceleration signal of the swing shaft was fast Fourier transformed. The time-domain signal of the vertical acceleration of the swing shaft was transformed to a frequency-domain signal. The experimental vertical acceleration frequency-domain curve of the swing shaft is shown in Figure 19. It can be seen that the vertical vibration of the swing shaft is a low-frequency vibration and the frequencies of vertical acceleration with high amplitude are $4 \mathrm{~Hz}$ and $69 \mathrm{~Hz}$. If we compare Figures 14 and 19, the simulation frequencies of vertical acceleration with high amplitude are very close to the experimental frequencies. The dynamic model of the COF machine is verified effectively.

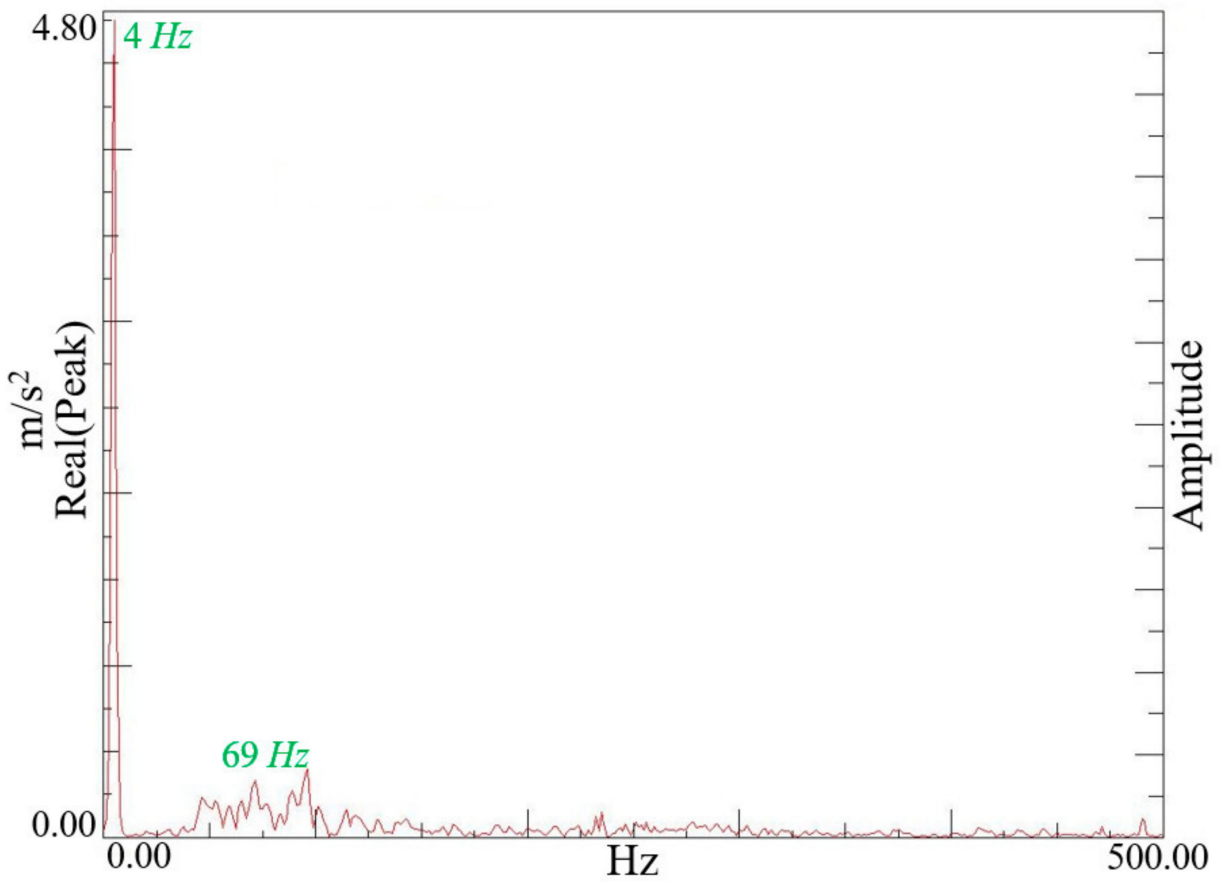

Figure 19. Vertical acceleration frequency-domain curve of the swing shaft. 


\section{Methods for Reducing Stress, Displacement and Vertical Vibration}

\subsection{Methods for Reducing Stress and Displacement}

As shown in the finite element simulation results of the static analysis, large equivalent stress positions and large displacement positions are mainly distributed near the working table and the junction between the working table and the inside of the column. The large stress and large displacement of these positions are bad for the quality of the part and the fatigue life of the COF machine. In order to reduce the stress and displacement of these positions, a structural optimization method for the COF machine can be carried out.

The structural optimization method of the COF machine is shown in Figure 20. Ribbed plates were added on the working table and the beam.

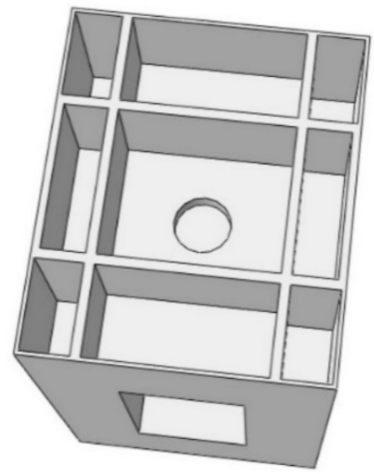

(a)

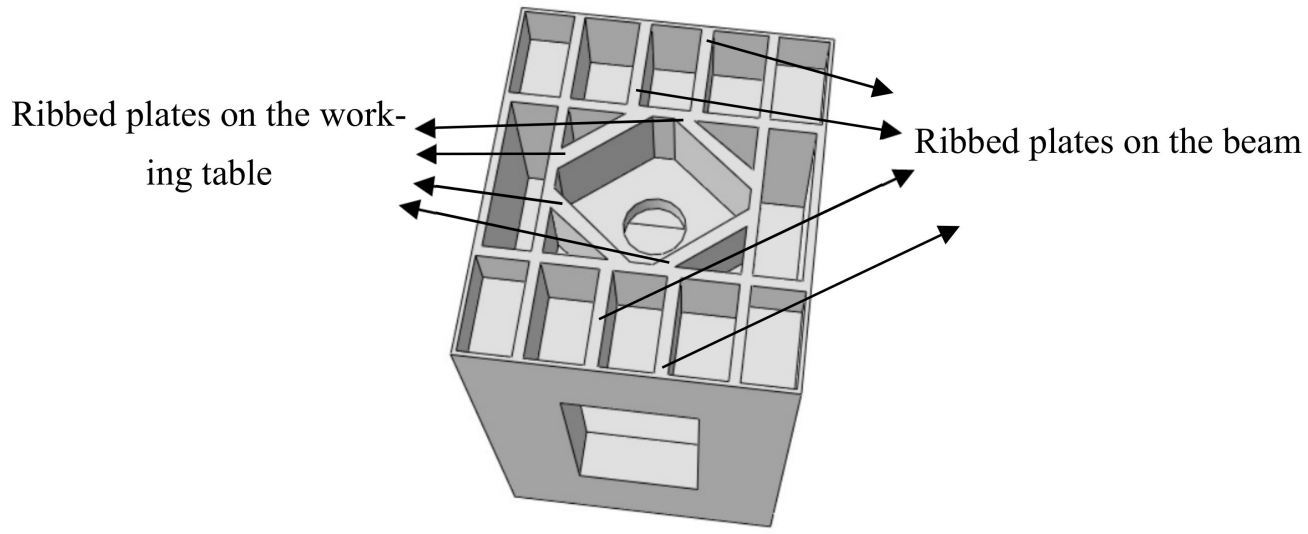

(b)

Figure 20. Initial structure (a) and optimized structure (b) of the COF machine.

In order to study the effect of the structural optimization method on the COF machine, a static simulation of the optimized COF machine was carried out. The static equivalent stress and static displacement of the optimized COF machine are shown in Figure 21. The maximum equivalent stress of the optimized COF machine (80.2 MPa) was far less than the maximum equivalent stress of the initial COF machine (112.5 MPa). The maximum displacement of the optimized COF machine $(0.4268 \mathrm{~mm})$ was much less than the maximum displacement of the initial COF machine $(0.7267 \mathrm{~mm})$. The structural optimization method of the COF machine obviously reduced the stress and displacement of the COF machine. 

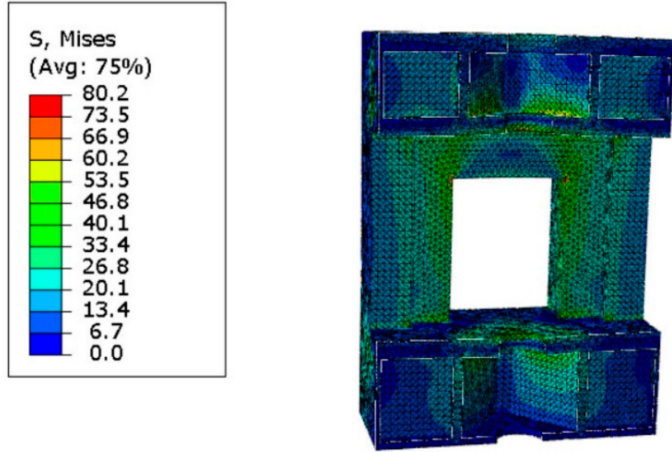

(a)
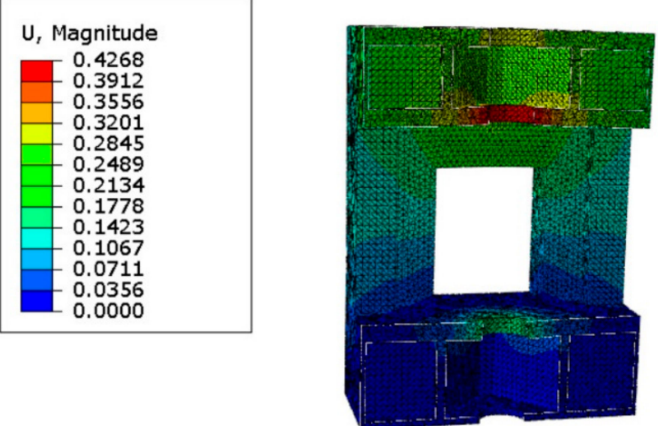

(b)

Figure 21. Static equivalent stress (a) and static displacement (b) of the optimized COF machine.

\subsection{Methods for Reducing Vertical Vibration}

As shown in the numerical simulation results of the dynamic analysis, the vertical vibration of the swing shaft was large. The large vertical vibration of the swing shaft will be bad for the quality of the part and the fatigue life of the COF machine. In order to reduce the vertical vibration of the swing shaft, an absorber was set on the swing shaft. A vertical dynamic model of the swing shaft is shown in Figure 22, where $z_{4}$ is the absolute displacement of the absorber $(\mathrm{m}), k_{2}$ is the equivalent stiffness between the swing shaft and absorber $(\mathrm{N} / \mathrm{m}), c_{2}$ is the equivalent damping between the swing shaft and absorber $(\mathrm{N} \cdot \mathrm{S} / \mathrm{m})$ and $m_{4}$ is the equivalent mass of the absorber $(\mathrm{kg})$.
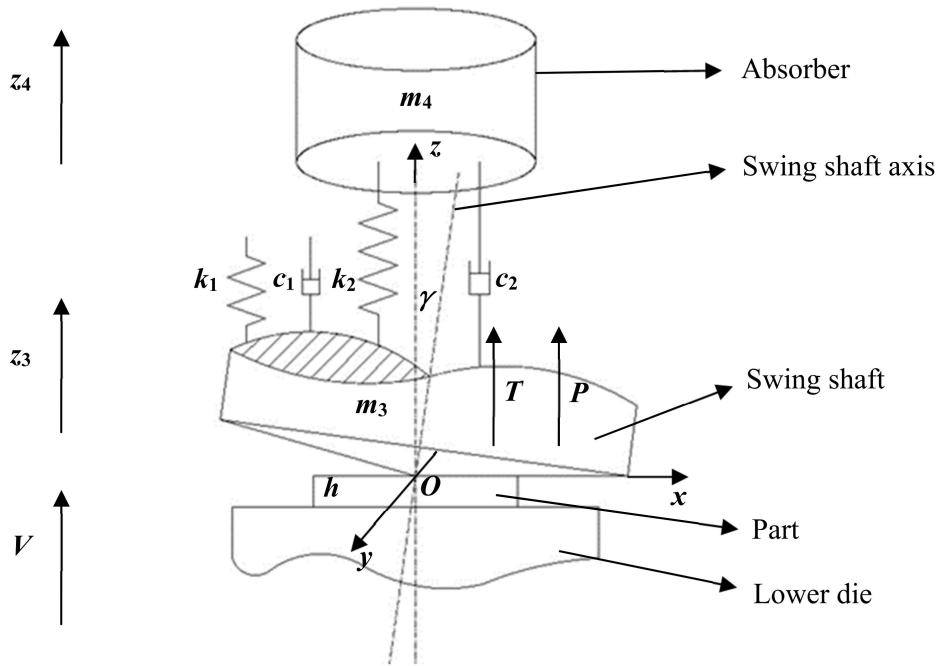

Figure 22. Vertical dynamic model of the swing shaft. 
According to the generalized dissipation Lagrange principle, the vertical dynamic equation of swing shaft can be expressed by Equation (17).

$$
\left\{\begin{array}{l}
m_{3} \ddot{z}_{3}+c_{1} \dot{z}_{3}+k_{1}\left(z_{3}+z_{0}\right)+c_{2}\left(\dot{z}_{3}-\dot{z}_{4}\right)+k_{2}\left(z_{3}-z_{4}\right)-P\left(z_{3}\right)=T \\
m_{4} \ddot{z}_{4}-c_{2}\left(\dot{z}_{3}-\dot{z}_{4}\right)-k_{2}\left(z_{3}-z_{4}\right)=0
\end{array}\right.
$$

where $z_{0}$ is equilibrium point in the COF process. In the process of steady-state $\mathrm{COF}$ $\left((T=0), z_{3}=0, \dot{z}_{3}=0, \ddot{z}_{3}=0\right)$, the equilibrium equation below can be obtained:

$$
k_{1} z_{0}-P(0)=0
$$

Equation (17) can be converted into Equation (19):

$$
\left\{\begin{array}{l}
\ddot{z}_{3}+\omega_{0}^{2} z_{3}-\alpha z_{3}^{2}-\beta \dot{z}_{3}-\eta z_{3}^{3}-\gamma \dot{z}_{4}-\delta z_{4}=T_{0} \\
\ddot{z}_{4}+\rho \dot{z}_{4}+\sigma z_{4}-\rho \dot{z}_{3}-\sigma z_{3}=0
\end{array}\right.
$$

where $\omega_{0}, \alpha, \beta, \eta$ and $T_{0}$ can be expressed by the following:

$$
\left\{\begin{array}{l}
\omega_{0}=\sqrt{\frac{k_{1}+k_{2}-b_{1}}{m_{3}}} \alpha=\frac{b_{2}}{m_{3}} \beta=-\frac{c_{1}+c_{2}}{m_{3}} \eta=\frac{b_{3}}{m_{3}} T_{0}=\frac{T}{m_{3}}=\frac{F \sin \omega t}{m_{3}}=F_{0} \sin \omega t \\
\gamma=\frac{c_{2}}{m_{3}} \delta=\frac{k_{2}}{m_{3}} \rho=\frac{c_{2}}{m_{4}} \sigma=\frac{k_{2}}{m_{4}}
\end{array}\right.
$$

The vertical acceleration frequency-domain curve of the swing shaft is shown in Figure 23. If we compare Figures 14 and 23, existence of the absorber obviously reduced the vertical vibration of the $\mathrm{COF}$ machine.

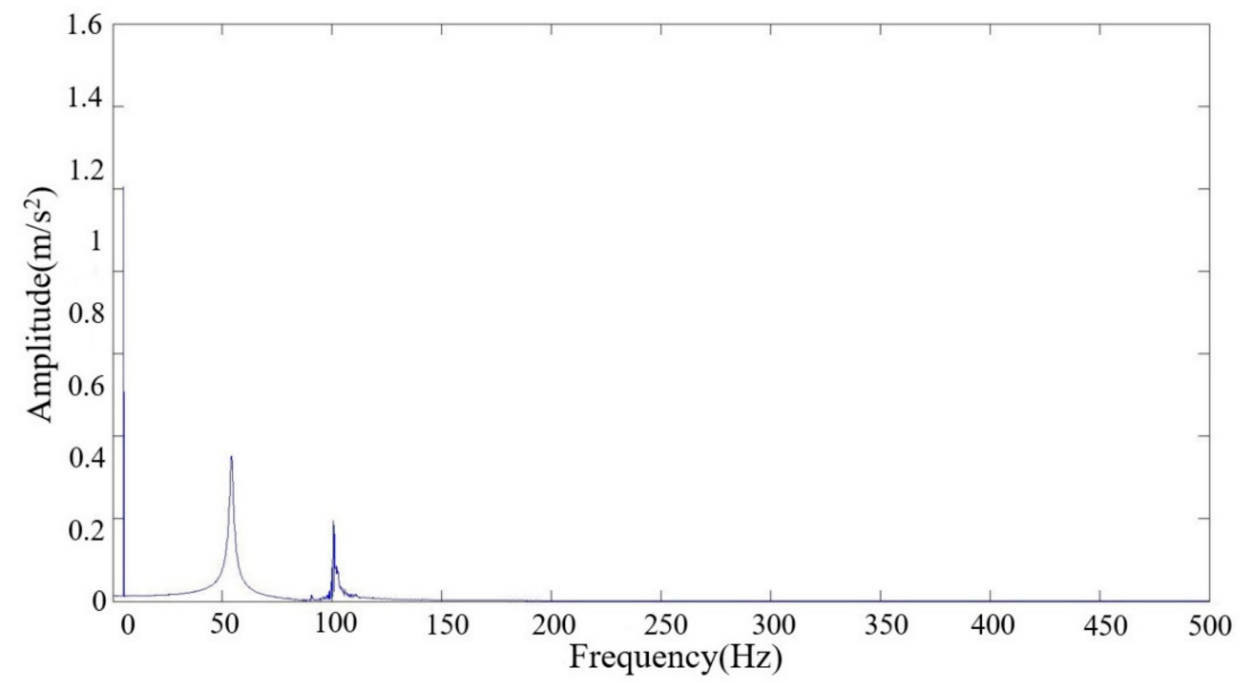

Figure 23. Vertical acceleration frequency-domain curve of the swing shaft.

\section{Conclusions}

In this study, finite element analysis, theoretical analysis, numerical simulation and experimental analysis were applied to analyze the static performance and dynamic performance of the COF machine. The static and dynamic analyses were verified effectively by carrying out strain and vertical vibration test experiments of a $6300 \mathrm{KN}$ COF machine. In the static and dynamic analyses of the COF machine, large stress positions, large displacement positions and vertical vibration performance are explicit. According to the large stress positions and large displacement positions of the COF machine, a structural optimization method for the COF machine was put forward to reduce stress and displacement. Based on the vertical dynamic model, an absorber was set to reduce vertical vibration. Several conclusions can be drawn as follows:

In the static analysis, the large stress positions of the COF machine were mainly distributed near the working table and the junction between the working table and the 
inside of the column. The large displacement positions were mainly distributed near upper and lower working tables. The maximum equivalent stress of the COF machine was less than the allowable stress of the material of the COF machine. In the COF process, material yield will not take place in the COF machine. However, large stress and displacement positions will be bad for the quality of the part and the fatigue life of the COF machine. In order to reduce the stress and displacement of these positions, structural optimizations of the COF machine was conducted. The structural optimization of the COF machine involved ribbed plates on the working table and the beam. The structural optimization of the COF machine obviously reduced the stress and displacement of the COF machine.

In the dynamic analysis, when the angular velocities of the inner and outer eccentric ring were $8 \pi \mathrm{rad} / \mathrm{s}$, the peak values of the frequency-domain curve of vertical vibration arose a $4 \mathrm{~Hz}$ and $61 \mathrm{~Hz}$ and the vertical vibration of the swing shaft was a low-frequency vibration. The frequency interval between the two peaks of the frequency-domain curve of vertical vibration was larger, the vertical vibration of the swing shaft was relatively stable. However, the vertical vibration of the swing shaft will be bad for the quality of the part and the fatigue life of the COF machine. In order to reduce the vertical vibration of the swing shaft, the absorber was set up on the swing shaft. The existence of the absorber obviously reduced the vertical vibration of the COF machine.

In this study, static performance and dynamic performance were analyzed and methods were put forward for reducing the stress, displacement and vertical vibration of the $\mathrm{COF}$ machine. The investigations in this paper contribute to improving the quality of the part and the fatigue life of the COF machine.

Author Contributions: Z.G.: investigation, supervision, writing-original draft preparation. M.C.: methodology, resources, writing-review and editing. C.W.: writing-review and editing. W.Z.: funding acquisition, writing-review and editing. All authors have read and agreed to the published version of the manuscript.

Funding: The authors would like to thank the National Natural Science Foundation of China (No. 51575416), the National Natural Science Foundation of China Youth Fund (52005375), the Independent Innovation Foundation of Wuhan University of Technology (2019IVA102) and the China Postdoctoral Science Foundation (2020M672429) for the support given to this research.

Conflicts of Interest: The authors declare no conflict of interest.

\section{References}

1. Han, X.; Hua, L.; Zhuang, W.; Zhang, X. Process design and control in cold rotary forging of non-rotary gear parts. J. Mater. Process. Technol. 2014, 214, 2402-2416. [CrossRef]

2. Jiao, M.; Guo, X.H.; Wan, D.D. Finite element analysis and lightweight research on the bed of arge machine tool based on HyperWorks. Appl. Mech. Mater. 2011, 121-126, 3294-3298. [CrossRef]

3. Zou, H.; Wang, B.; Song, F.; Fu, L. The application of mineral casting in high-precision printed circuit board drilling machine. Circuit World 2013, 39, 204-211. [CrossRef]

4. Markowski, T.; Mucha, J.; Witkowski, W. FEM analysis of clinching joint machine's C-frame rigidity. Eksploat. Niezawodn.-Maint. Reliabi. 2013, 15, 51-57.

5. Syam, W.P.; Jianwei, W.; Zhao, B.; Maskery, I.; Elmadih, W.; Leach, R. Design and analysis of strut-based lattice structures for vibration isolation. Precis. Eng. J. Int. Soc. Precis. Eng. Nanotechnol. 2018, 52, 494-506. [CrossRef]

6. Irfan, S.; Siddiqui, F. A review of recent advancements in finite element formulation for sandwich plates. Chin. J. Aeronaut. 2019, 32, 785-798. [CrossRef]

7. Gohari, S.; Sharifi, S.; Sharifishourabi, G.; Vrcelj, Z.; Abadi, R. Effect of temperature on crack initiation in gas formed structures. J. Mech. Sci. Technol. 2013, 27, 3745-3754. [CrossRef]

8. Sherbakov, S.S. Three-Dimensional Stress-Strain State of a Pipe with Corrosion Damage under Complex Loading. In TribologyLubricants and Lubrication; BoD-Books on Demand: Norderstedt, Germany, 2011.

9. Sherbakov, S.S.; Zhuravkov, M.A. Interaction of several bodies as applied to solving tribo-fatigue problems. Acta Mech. 2013, 224, 1541-1553. [CrossRef]

10. Shcherbakov, S.S. Spatial stress-strain state of tribofatigue system in roll-shaft contact zone. Srength Mater. 2013, 45, 35-43. [CrossRef]

11. Sherbakov, S.S. Measurement and real time analysis of local damage in wear-and-fatigue tests. Devices Methods Meas. 2019, 10, 207-214. [CrossRef] 
12. Sosnovskiy, L.A.; Sherbakov, S.S. On the development of mechanothermodynamics as a new branch of physics. Entropy 2019, 21, 1188. [CrossRef]

13. Li, B.; Cai, H.; Mao, X.; Huang, J.; Luo, B. Estimation of CNC machine-tool dynamic parameters based on random cutting excitation through operational modal analysis. Int. J. Mach. Tools Manuf. 2013, 71, 26-40. [CrossRef]

14. Liu, F.; Liu, B.; Liu, H.R.; Gong, Y.L.; Wang, S.J. Vertical vibration of strip mill with the piecewise nonlinear constraint arising from hydraulic cylinder. Int. J. Precis. Eng. Manuf. 2015, 16, 1891-1898. [CrossRef]

15. Bar, A.; Swiatoniowski, A. Interdependence between the rolling speed and non-linear vibrations of the mill system. J. Mater. Process. Technol. 2004, 155-156, 2116-2121. [CrossRef]

16. Lu, X.; Sun, J.; Li, G.; Wang, Q.; Zhang, D. Dynamic analysis of vibration stability in tandem cold rolling mill. J. Mater. Process. Technol. 2019, 272, 47-57. [CrossRef]

17. Lu, X.; Sun, J.; Li, G.; Wang, Z.; Zhang, D. Stability analysis of a nonlinear coupled vibration model in a tandem cold rolling mill. Shock Vib. 2019, 2019, 4358631. [CrossRef]

18. Kim, Y.; Kim, C.W.; Lee, S.; Park, H. Dynamic modeling and numerical analysis of a cold rolling mill. Int. J. Precis. Eng. Manuf. 2013, 14, 407-413. [CrossRef]

19. Kim, Y.; Kim, C.W.; Lee, S.J.; Park, H. Experimental and numerical investigation of the vibration characteristics in a cold rolling mill using multibody dynamics. ISIJ Int. 2012, 52, 2042-2047. [CrossRef]

20. Zhao, X.; Liu, Y.; Hua, L.; Mao, H. Finite element analysis and topology optimization of a $12000 \mathrm{KN}$ fine blanking press frame. Struct. Multidiscip. Optim. 2016, 54, 375-389. [CrossRef]

21. Li, C.; Kim, I.Y.; Jeswiet, J. Design space and detailed design of an automotive engine cradle by using topology, shape, and size optimization. Struct. Multidiscip. Optim. 2015, 51, 547-564. [CrossRef]

22. Strano, M.; Monno, M.; Rossi, A. Optimized design of press frames with respect to energy efficiency. J. Clean Prod. 2013, 41, 140-149. [CrossRef]

23. Duan, Z.D.; Wu, J.J. Topological Optimization of Frame of High Speed Hydraulic Press Based on Generalized Finite Element Modules. Appl. Mech. Mater. 2010, 44-47, 1828-1832. [CrossRef]

24. Xu, D.K.; Chen, J.; Tang, Y.C.; Cao, J. Topology optimization of die weight reduction for high-strength sheet metal stamping. Int. J. Mech. Sci. 2012, 59, 73-82. [CrossRef]

25. Yan, Y.N.; Jing, H.; Zhang, D.J.; Chen, Z.D.; Huang, X.F. Optimization design of heavy load-bearing frame-Discussing about the 1200MN hydraulic press: I. Forg. Stamp. Technol. 2013, 38, 1-13.

26. Han, X.H.; Hua, L. 3D FE modelling of contact pressure response in cold rotary forging. Tribol. Int. 2013, 57, 115-123. [CrossRef]

27. Han, X.; Hu, Y.; Hua, L. Cold orbital forging of gear rack. Int. J. Mech. Sci. 2016, 117, 227-242. [CrossRef]

28. Oudin, J.; Ravalard, Y.; Verwaerde, G.; Gelin, J.C. Force, torque and plastic flow analysis in rotary upsetting of ring shaped billets. Int. J. Mech. Sci. 1985, 27, 761-780. [CrossRef]

29. Canta, T.; Frunza, D.; Sabadus, D.; Tintelecan, C. Some aspects of energy distribution in rotary forming processes. J. Mater. Process. Technol. 1998, 80, 195-198. [CrossRef]

30. Han, X.H.; Zhang, X.C.; Hua, L. Calculation method for rocking die motion track in cold orbital forging. J. Manuf. Sci. Eng. 2016, 138, 014501. [CrossRef]

31. Han, X.H.; Zhang, X.C.; Hua, L. Calculation of kinetic locus of upper tool in cold orbital forging machine with two eccentricity rings. J. Mech. Sci. Technol. 2015, 29, 4351-4358. [CrossRef]

32. Feng, W.; Yao, W.; Jiang, P. Influence of eccentricity on movements of orbital head with double eccentric structure in orbital forging. Procedia Eng. 2014, 81, 2348-2354. [CrossRef]

33. Dong, L.; Han, X.; Hua, L.; Lan, J.; Zhuang, W. Effects of the rotation speed ratio of double eccentricity bushings on rocking tool path in a cold rotary forging press. J. Mech. Sci. Technol. 2015, 29, 1619-1628. [CrossRef] 